\title{
Academic Self Efficacy and Dispositional Hope as Predictors of Academic Procrastination: The Mediating Effect of Academic Intrinsic Motivation
}

\author{
Kayhan Bozgun* \\ Department of Primary Education, Faculty of Education, Amasya University, Amasya, Turkey \\ ORCID: 0000-0001-9239-2547
}

Kemal Baytemir

Department of Educational Sciences, Faculty of Education, Selcuk University, Konya, Turkey ORCID: 0000-0002-7865-4325

\begin{tabular}{|c|c|}
\hline Article history & This study aims at determining the mediating effect of academic intrinsic \\
\hline $\begin{array}{l}\text { Received: } \\
24.05 .2021\end{array}$ & $\begin{array}{l}\text { motivation on the relationship between both students' academic self- } \\
\text { efficacy and dispositional hope levels to their academic procrastination }\end{array}$ \\
\hline $\begin{array}{l}\text { Received in revised form: } \\
04.11 .2021\end{array}$ & $\begin{array}{l}\text { habits. The data were collected from a sample of } 252 \text { college students, } \\
69 \text { males }(27.4 \%) \text { and } 183 \text { females }(72.6 \%) \text {, aged between } 18 \text { and } 33(\mathrm{X} \\
=20.55 ; \mathrm{Sd}=1.52) \text { studying at a state university located in the Central }\end{array}$ \\
\hline $\begin{array}{l}\text { Accepted: } \\
19.11 .2021\end{array}$ & $\begin{array}{l}\text { Black Sea region of Turkey using a correlational survey model. } \\
\text { Academic Self Efficacy Scale, Dispositional Hope Scale, Academic }\end{array}$ \\
\hline Key words: & Intrinsic Motivation Scale, and Aitken Academic Procrastination Scale \\
\hline $\begin{array}{l}\text { Academic self-efficacy; } \\
\text { academic intrinsic motivation; } \\
\text { academic procrastination; } \\
\text { dispositional hope; college } \\
\text { students }\end{array}$ & $\begin{array}{l}\text { were used as data collection tools. Descriptive statistics of the socio- } \\
\text { demographic characteristics were presented, and Pearson correlation } \\
\text { analysis was conducted to determine the correlations between variables } \\
\text { by using SPSS statistical package programme. The hypothesis } \\
\text { measurement model and the mediating effect were examined by } \\
\text { Structural Equation Modeling (SEM) by using LISREL statistical } \\
\text { software. The obtained results showed that significant (low and } \\
\text { moderate) relationships exist between variables and the model tested in } \\
\text { the study yielded acceptable and good fit index values. A complete } \\
\text { mediating effect of academic intrinsic motivation on the relationship } \\
\text { between both academic self-efficacy and dispositional hope with } \\
\text { academic procrastination was determined. The findings were discussed, } \\
\text { and some recommendations were made. }\end{array}$ \\
\hline
\end{tabular}

\section{Introduction}

It is common for individuals to postpone their work in some periods of their lives thinking that they can be done later. Procrastination can lead to suspend or completely stop a task (Milgram, Mey-Tal \& Levison, 1998; Pychyl, Morin \& Salmon, 2000; Sirois \& Pychyl, 2013). Regardless of age, procrastination of a task can negatively affect belief in starting a new task. Procrastination behavior differs from person to person. While some people exhibit procrastination behavior only in a part of life, some display procrastination as a personality trait. Accordingly, it is unlikely to find someone who did not postpone any task in his lifetime

\footnotetext{
*Correspondency: kayhanbozgun@gmail.com
} 
(Senecal, Koestner \& Vallerand, 1995). The search for answers to the questions, "How to define a procrastinating person? or who are procrastinating people?" shows the importance of identifying the disadvantages of procrastination.

College students also exhibit procrastination behavior (Hill, Hill, Chabot \& Barrall, 1978). This procrastination behavior displayed by students called academic procrastination (AP). Day, Mensink and O'Sullivan (2000) conducted a comprehensive study to determine variables related to academic procrastination and they highlighted that academic procrastination is a common problem among college students. Some students procrastinate making their necessary repetitions and can fail accordingly. On the other hand, while assuming that they are procrastinating just for a few days, some students enter in a procrastination loop and are surprised when it comes to exam week. Although they have passed their tests, completed their assignments, and did their tasks, procrastination of studying always leads to a negative consequence and negatively affects students' academic success (Beck, Koons \& Milgrim, 2000; Hill et al., 1978). The decrease in academic performance and success in students who exhibit procrastination behaviors can be given as an example of this situation (Solomon \& Rothblum, 1984). However, it is not correct to consider every procrastinating student as unsuccessful. The important point to be emphasized here is that procrastination causes negative interruptions and delays on the way to success (Milgram et al., 1998).

When students postpone an assignment, even for a short time, they may experience an instantaneous pleasure that is, relaxation however, they may feel anxiety about not being able to finish on time and not being able to succeed (Akbay \& Gizir, 2010). Since procrastination negatively affects not only academic success but also health, it can have a deep impact on our lives. It is inevitable to experience health problems due to variables that negatively affect wellbeing such as stress and anxiety created by the accumulated tasks and responsibilities as a result of procrastination behaviors (Ellis and Knaus, 1977; Ferrari and Beck, 1998; Solomon and Rothblum, 1984; Tice and Baumeister, 1997). According to Sirois and Pychyl (2013), individuals with higher rates of procrastination habits had lower rates of health and well-being. Therefore, it can be argued that academic procrastination has a negative impact not only on students' academic performance but also on their health.

The following question can be asked here: What is the underlying reason for students' academic procrastination? What are the factors that cause academic procrastination? What are the variables related to academic procrastination? What are the precursor factors? Many studies were carried out for years to find answers to these questions (Aitken, 1982; Balk1s, 2006; Balkıs, Duru, Buluş \& Duru, 2006; Day et al., 2000; Hill et al., 1978; Milgram et al., 1998; Senecal et al., 1995; Solomon and Rothblum, 1984) Based on the findings of these studies, test of integrative models explaining underlying factors of academic procrastination can provide valuable insights into academic procrastination behaviors. Academic procrastination is not only slowing down a task or postponing it to a later date, it also depends on the existence of variables that cause the procrastination (Sirois \& Pychyl, 2013; Urban, 2013). In this regard, the authors believe that the identification of the reasons for college students' academic procrastination behaviors and variables predicting procrastination behaviors can make significant contributions to the literature. 


\section{Theoretical framework}

\section{Definition of academic procrastination and its characteristics}

Since procrastination consists of many different structures such as behavioral, cognitive, and affective (Solomon \& Rothblum, 1984), different definitions are made. According to Uzun Özer (2009), the reasons for procrastination are explained differently by psychoanalytic, cognitive behavioral, and behavioral theorists. Some of these reasons are avoidance behavior, irrational beliefs, or acquired momentary pleasures.

In general, procrastination can be defined as a personality trait and described as a tendency to procrastinate or postpone doing a task or making a decision (Milgram et al., 1998; Solomon \& Rothblum, 1984). In addition to reducing one's productivity, procrastination can cause exhibiting task-avoidance behaviors. Solomon and Rothblum (1984) defined the underlying reasons of procrastination as task avoidance, fear of failure, and negative perceptions and beliefs.

Urban (2013) emphasized that procrastination is an uncontrollable behavior and delaying cannot be avoided with a thought such as "I should start doing the task immediately so that I will not delay". Similarly, Pychyl (2013) carried out studies on procrastination and stated that procrastination is not a time management or laziness problem, procrastination could only be defined as procrastination. Procrastination is also defined as failure to regulate emotions. Urban (2013) highlighted the momentary pleasures as the reason for procrastination and argued that procrastination can be prevented by giving up momentary pleasures, which he defined as a rational decision-making process, with conscious attention to accomplish the task.

Academic procrastination, which is defined as a sub-type of procrastination, has similar characteristics to procrastination and is a situation where the student experiences difficulties due to delays in the learning process or academic tasks (Akbay \& Gizir, 2010). Academic procrastination is known as one of the most common problems among students (Mohammadipour \& Rahmati, 2016). This behavior occurs especially when faced with a deterrent task that a student perceives as difficult and also has negative impacts on students' health (Sirois \& Pychyl, 2013). It was reported that students with high academic procrastination behavior were studying less and more procrastinate studying compared to those with low academic procrastination behaviors (Pychyl et al., 2000). Tim Urban, a famous TED speaker, in his study (2013) on procrastination, stated that procrastination is not a habit or behavior but is a unique situation that can be experienced from time to time. Furthermore, Urban argues that to avoid procrastination, one should continue their tasks every day, without giving up, with certain self-discipline.

According to previous studies on academic procrastination, it is positively related to dispositional hope (DH), motivation, academic intrinsic motivation (AIM), self-regulation and academic self-efficacy skills (ASE), self-respect, success orientation, decision making, and thinking styles; and negatively related to the negative attitudes towards learning, ineffective time management, depression and anxiety, as well as associated with many cognitive and affective factors (Balkıs, 2006; Balkıs et al., 2006; Brownlow \& Reasinger, 2000, Orpen, 1998; Senecal \& Guay, 2000; Senecal et al., 1995). A study by Solomon and Rothblum (1984) revealed that some concepts such as depression and irrational beliefs are related to academic procrastination and its reasons. Pychyl (2013) emphasized that teachers and parents should teach children to deal with procrastination from an early age and awareness should be raised that procrastination is not a time management problem, but an emotional management problem. 


\section{The relationship between academic procrastination and Academic self-efficacy and hope}

It was stated that procrastinating individuals have negative self-perception and low selfefficacy perceptions, which is one of the sub-dimensions of this perception (Martin, Flett, Hewitt, Krames \& Szanto, 1996). The results obtained in another study indicated that one of the reasons for academic procrastination is related to low self-efficacy (Seo, 2008). Therefore, academic self-efficacy can be considered an important variable predicting academic procrastination in college students.

Self-efficacy refers to students' belief that they can successfully accomplish a specific academic goal, activity, or task (Bandura, 1986). Self-efficacy, which is defined by Bandura (1997) as a belief to achieve any goal refers to the belief and determination to accomplish any task. On the other hand, academic self-efficacy is defined as the belief to accomplish academic goals or academic success (Pajares \& Graham, 1999) and consists of students' self-judgments. While positive self-judgments allow a student to be more determined and more successful in solving problems, positive self-judgments lead to giving up from these behaviors and cause students to lose their motivation towards the task they are doing, fear of failure and abandon doing that task in a short time (Bandura, 1997). The presence of fear of failure and losing faith to accomplish the task, which play a role in exhibiting procrastination behavior, indicates that the individual has low self-efficacy skills (Moshtaghi \& Moayedfar, 2017).

Many studies have emphasized the impact of self-efficacy on procrastination behavior which many college students exhibit from time to time (Kandemir, 2010; Katz et al., 2014; Martin et al., 1996; Moshtaghi \& Moayedfar, 2017; Steel, 2007; Tripathi, Kochar \& Dara, 2015). In this regard, self-efficacy is an important skill for college students to accomplish their tasks and responsibilities. Some studies highlighted that academic procrastination behavior increase as academic self-efficacy decrease (Kandemir, 2010; Moshtaghi \& Moayedfar, 2017; Tripathi et al., 2015).

Academic procrastination does not depend only on low self-efficacy. Since procrastination tendency is defined as not only the loss of belief in success, but also a failure in emotion management, affective factors also have an impact on procrastination behavior. Hope is one of these factors (Moshtaghi \& Moayedfar, 2017; Senecal \& Guay, 2000). Since hope, which consists of agency thoughts and pathways, is a motivational act, low motivation can lead to a tendency of procrastination with reduced hope.

Hope is a state of mind related to taking actions for personal desires and goals, making realistic and internally motivating evaluations while trying to achieve these goals and having positive expectations (Snyder et al., 1991). Considering from this point of view, goal and motivation are the indicators of Snyder's hope theory. As the perceived motivation increases hope increases (Snyder, 2002). Snyder et al. (1991) found that individuals with higher hope have a purpose in life, which is an indicator of self-efficacy skills, and these individuals were more willing, productive, and active in dealing with difficulties and responsibilities as well as creating strategies to achieve these goals. They discussed the Dispositional Hope Scale under two subdimensions of agency and pathways thoughts. The pathways thoughts refer to finding practicable ways and creating alternative strategies to achieve the designated goal. On the other hand, agency thoughts are related to motivation. It refers to the motivation that one perceives intrinsically while achieving their goal (Snyder et al., 1991; Tarhan \& Bacanl1, 2015). Individuals with hope achieve their goals by motivating themselves with an inner speech that they will find a solution to the difficulties they faced (Snyder, Lapointe, Crowson \& Early, 1998). Martin (2007) argued that people with higher levels of hope were more optimistic and 
healthier, on the other hand, those with lower levels of hope had internal problems and difficulties.

Previous studies have shown that significant correlations exist between hope and motivation (Snyder et al., 1998), self-efficacy (Snyder, 2002), having a valid basis and problem-solving skills (Martin, 2007), and academic procrastination (Moshtaghi \& Moayedfar, 2017; Odacı \& Kaya, 2019; Senecal \& Guay, 2000; Uzun Özer, 2009). Roesch et al. (2010) found that students with dispositional hope and coping skills had very low academic procrastination problems. Moreover, positive relationships were determined between dispositional hope and planning and problem-solving skills and coping with stress. Senecal and Guay (2000) determined that a correlation exists between hope and procrastination and stated that procrastination depends on the level of hope. Hope is an important factor for college students as professional individuals of the future since hope and self-efficacy can reduce procrastination. Accordingly, a constant state of hope and optimism is necessary for an individual to continue living positively.

Seo (2008) used a structural equation modeling approach and found a negative correlation between academic procrastination and self-efficacy, in which self-efficacy is a predictor of academic procrastination. Mohammadipour and Rahmati (2016) stated that students' hope and self-efficacy are related to academic procrastination behaviors and accordingly, a low level of hope is a reason for procrastination. Similarly, Tripathi et al. (2015) determined a relationship between both self-efficacy and hope with academic procrastination and they found that higher levels of hope indicate a low tendency to procrastination. It is a known fact that as levels of hope increase, students' beliefs towards achieving their goals, that is, their self-efficacy increase and procrastination decrease (Alexander \& Onwuegbuzie, 2007). According to the results of previous studies, both self-efficacy and hope have an impact on students' academic procrastination behaviors. In this regard, hope and self-efficacy are considered important factors since their presence can decrease students' academic procrastination behaviors.

\section{The relationship between academic internal motivation and academic procrastination}

In addition to the relation of self-efficacy and hope to academic procrastination, the examination of the relation of motivation, which is closely associated with hope, to procrastination is also important. It was determined that students with higher levels of motivation, also known as impetus, were more successful in accomplishing their tasks (Akbay \& Gizir, 2010). Since students' higher academic motivation increases their willingness to accomplish their tasks, it can be argued that they will display less procrastination behavior. Balkis (2006) found that motivation sources are significant predictors of procrastination tendency.

Academic internal motivation is defined as internal processes that control one's behaviors to achieve their academic goals and increase their willingness (Pintrich \& Zusho, 2002). According to Self-Determination theory which indicates students are responsible for their own decisions and life, motivation should be examined under two sub-dimensions: intrinsic motivation and extrinsic motivation (Ryan \& Deci, 2000; Wang \& Guthire, 2004). While intrinsic motivation refers to behavior driven by internal rewards such as start and continue doing of an activity for its inherent satisfaction; extrinsic motivation is about starting and continue doing of an activity purely for outside rewards (Ryan \& Deci, 2000). For learning processes, cultivating intrinsic motivation is important.

Orpen (1998) emphasized that low intrinsic motivation has an important impact on individuals' procrastination behaviors. Many studies have shown that intrinsic motivation is effective on 
academic procrastination and as students' intrinsic motivation increases their tendency to academic procrastination decreases (Akpur, 2017; Brownlow \& Reasinger, 2000; Katz et al., 2014; Senecal et al., 1995; Yeşiltaş, 2020). Akbay \& Gizir (2010) found that academic selfefficacy and academic motivation predict students' academic procrastination behaviors.

\section{The relation of academic self-efficacy and hope to academic intrinsic motivation}

Academic self-efficacy refers to one's ability to accomplish a task successfully and to cope with challenges that emerged in this period (Bandura, 1977). Furthermore, it also contributes to willingness and motivation for learning (Bandura, 1995; Sparks, 1988). Many studies have shown that there is a correlation between self-efficacy and intrinsic motivation (Alemdağ, Erman \& Y1lmaz, 2014; Koca \& Dadand1, 2019; Tekke \& Y1ldız, 2020). The results obtained in these studies indicated that motivation increases in the case of higher academic selfefficacy. In a study by Malkoç and Kesen Mutlu (2018), the authors found that academic intrinsic motivation mediated the relationship between self-efficacy and academic procrastination. Based on these results, it can be argued that academic self-efficacy and academic intrinsic motivation are factors significantly related to effective learning.

From the perspective of positive psychology, many studies have examined the relationship between motivation and some internal psychological factors such as self-efficacy, selfpersonality (Alemdağ et al., 2014; Koca \& Dadand1, 2019; Tekke \& Y1ld1z, 2020). However, only a limited number of studies have investigated the relationship between motivation and hope, which can be theoretically related to motivation (Mohammadipour \& Rahmati, 2016; Senecal \& Guay, 2000; Ulukan, 2020; Pala, 2019). In this regard, with advances in positive psychology, scholars have determined that students' beliefs and hopes towards their success have an important role in their success and they also claimed that hope is effective on motivation (Liu \& Cheng, 2018). Since hope is an expectation of achieving one's goals and reflects one's determination and beliefs in this process, it allows motivation to complete any tasks (Moltafet, 2020).

Mohammadipour and Rahmati (2016) stated that positive relationships exist between students' hope, self-efficacy, and motivations. Senecal and Guay (2000) found a positive correlation between academic intrinsic motivation and hope and this relationship has an impact on students' academic procrastination behaviors. Moshtaghi and Moayedfar (2017) conducted a study with college students, and they determined that academic procrastination is predicted by hope, selfefficacy, and success goals. Furthermore, they also found that hope and self-efficacy are negatively correlated with academic procrastination. Similarly, other studies have reported that as students' hope levels increase, their motivation increase (Ulukan, 2020; Pala, 2019). Based on these findings, students with higher levels of hope will display higher motivation for achieving their goals and accordingly, exhibit more effort.

\section{Importance and purpose of the study}

Solomon and Rothblum (1984) stated that procrastination tendency among college students differs with the situation, and they found that $46 \%$ of college students suffer academic procrastination. Ellis and Knaus (1977) reported this percentage as 95\%. On the other hand, it was found that almost $50 \%$ of college students in Turkey are procrastinating their tasks (Balk1s \& Duru, 2009; Uzun Özer, Demir \& Ferrari, 2009). These findings indicated that college students mostly exhibit procrastination behavior and prefer procrastination. As emphasized in the above-mentioned reports, it can be argued that academic procrastination may negatively affect students' college life as well as their career. In Turkey, the number of college graduates 
is increasing day by day, and accordingly, finding and getting into a job are becoming more difficult. While this fact may encourage and whip up students, it may also reduce their hope and motivation and therefore, lead to procrastination behavior. From this point of view, examining college students' procrastination behaviors and identifying related variables are important.

To the best of our knowledge, there are no studies that examined the mediating effect of academic intrinsic motivations on the relationship between college students' levels of selfefficacy and hope to academic procrastination. Some studies examined the relationship between academic procrastination and self-efficacy and hope (Moshtaghi \& Moayedfar, 2017) and some others examined the mediating effect of academic motivation on the relationship between academic procrastination and academic self-efficacy (Katz et al., 2014). However, the lack of a mediating model study including all these variables is obvious. Do low levels of self-efficacy and hope cause students' academic procrastination? Or, do students procrastinate since their academic intrinsic motivations decrease as a result of low levels of self-efficacy and hope? In this context, to seek answers to these questions, this study aims at examining whether the relationship between academic self-efficacy and hope levels, which have proven to be related to academic procrastination, is mediated by academic intrinsic motivation. The developed theoretical hypothesis model is given below.

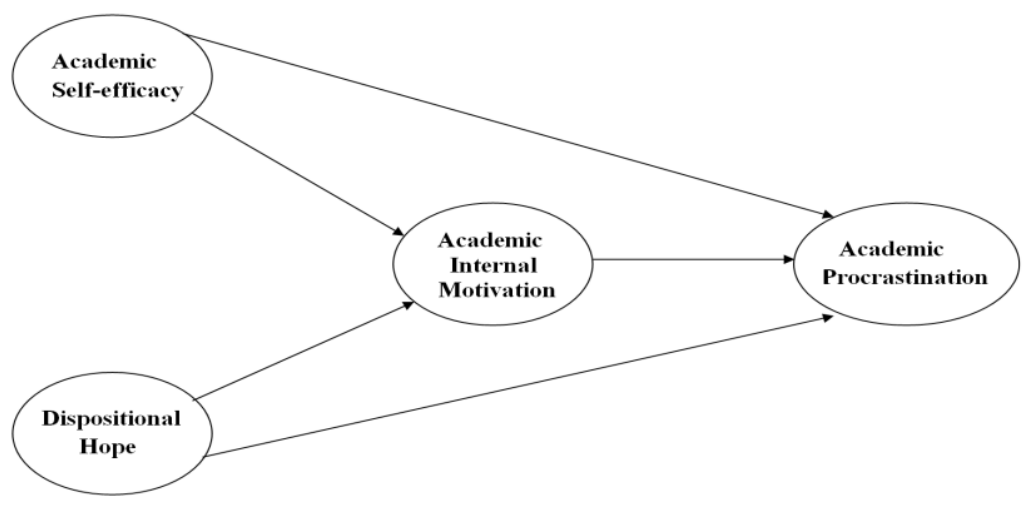

Figure 1. The hypothesis model for the mediating effect of academic intrinsic motivation on the relationship between academic self-efficacy and dispositional hope

As seen in Fig. 1, academic self-efficacy and dispositional hope are independent variables and academic procrastination is the dependent variable. Academic intrinsic motivation is the mediating variable on this relationship. For this hypothesis model, the following sub-questions were prepared:

(1) Do academic self-efficacy and dispositional hope predict students' academic procrastination behaviors?

(2) Does academic intrinsic motivation predict students' academic procrastination behaviors?

(3) Do academic self-efficacy and dispositional hope predict students' intrinsic motivation?

(4) Do academic self-efficacy and dispositional hope predict students' academic procrastination behaviors with the mediating effect of academic intrinsic motivation? 


\section{Method}

\section{Research Design}

Since this quantitative study examines the mediating effect of academic intrinsic motivation on the relationship between college students' academic self-efficacy and dispositional hope through structural equation modeling, a correlational survey model was designed. This method is used to identify whether two or more variables change together, the direction and strength of correlation (Fraenkel, Wallen \& Hyun, 2012).

\section{Study group}

This study was conducted with a study group consists of 252 students studying at the faculty of education of a state university located in the Central Black Sea region of Turkey. Convenience sampling strategy was used to identify the participants. Using this sampling strategy in current study, data collected from available individuals and required the demographic characteristics of the participants (Fraenkel, Wallen, \& Hyun, 2012). The distribution of students according to gender, age, program, and year in college is given in Table 1.

Table 1. Descriptive Statistics of Students' Demographic Characteristics

\begin{tabular}{lll}
\hline Variables & $\boldsymbol{n}$ & $\boldsymbol{\%}$ \\
\hline Gender & & \\
Male & 69 & 27.4 \\
Female & 183 & 72.6 \\
Year in college & & \\
1 & 70 & 27.8 \\
2 & 38 & 15.1 \\
3 & 105 & 41.7 \\
4 & 39 & 15.5 \\
Program & & \\
Physical education and sports teacher education & 32 & 12.7 \\
Science teacher education & 33 & 13.1 \\
English teacher education & 38 & 15.1 \\
Elementary Mathematics teacher education & 35 & 13.9 \\
Pre-school teacher education & 44 & 17.5 \\
Psychological Counseling and Guidance & 33 & 13.1 \\
Turkish teacher education & 37 & 14.7 \\
\hline
\end{tabular}

$N: 252$

As seen in Table 1, students in the faculty of education were $183(72.6 \%)$ females and 69 (27.4\%) males. Regarding the year in college, 70 (27.8\%) students were 1st-year students, 38 (15.1\%) were 2nd-year students, 105 (41.7\%) were 3rd-year students, and 39 (15.5\%) were 4thyear students. Regarding the program, $32(12.7 \%)$ students were at Physical education and sports teacher education program, $33(13.1 \%)$ were at Science teacher education program, 38 $(15.1 \%)$ were at English teacher education program, 35 (13.9\%) were at Elementary mathematics teacher education program, $44(17.5 \%)$ were at Pre-school teacher education program, $33(13.1 \%)$ were at Psychological Counseling and Guidance program, and $37(14.7 \%)$ students were at Turkish teacher education program. The age of the students was between 18 and 33 (Mean: 20.55; Sd: 1.52). 


\section{Data Collection Tools}

Academic Self Efficacy Scale, Dispositional Hope Scale, Academic Intrinsic Motivation Scale, and Aitken Academic Procrastination Scale were used as data collection tools in the study. Moreover, to determine students' demographic characteristics, a personal information sheet was prepared including four variables of gender, age, year in college, and program.

Academic Self Efficacy Scale: The scale was a 5-point Likert-type scale developed by Kandemir (2010) to measure students' perceptions of their academic performance by measuring academic self-efficacy. The scale consists of 19 items with sub-dimensions of self-efficacy for academic effort (4 items), self-efficacy for academic planning (4 items), and self-efficacy to cope with academic problems (11 items). The participants answered the survey items by marking one of the following options: (1) Strongly disagree, (2) Disagree, (3) Neither agree or disagree (4) Agree, (5) Strongly agree. The Exploratory Factor Analysis (EFA) results of original scale showed that Kaiser-Meyer-Olkin (KMO) coefficient was .93. Bartlett's test yielded a statistically significant and the factor loads varied between .54 and .78. Furthermore, Confirmatory Factor Analysis (CFA) results indicated that the three-factor model yielded better fit index values and the scale was decided as a valid measurement tool. Regarding internal consistency, while the Cronbach's alpha of the original scale was calculated as .91, it was calculated as .93 in the current study.

Dispositional Hope Scale: The scale was developed by Snyder et al. (1991) to determine adult dispositional hope. The adaptation study of the scale into the Turkish language was carried out by Tarhan and Bacanll (2015). The scale consists of two subscales: pathways thoughts (4 items) and agency thoughts (4 items) and distractor items that are not related to hope (4 items). The scale includes 12 items however, it can be used as an 8 item-scale if the distractor items are not used. The participant chooses the degree of agreement with each statement on an 8-point scale ranging from (1) definitely wrong to (8) definitely true. EFA and CFA results of original scale showed that the KMO coefficient of the scale was calculated as .90 , Bartlett's test yielded a statistically significant value, and two subscales explained $61 \%$ of the total variance. Additionally, the two-factor model yielded good and acceptable fit index values and the scale was decided as a valid measurement tool. While the internal consistency of the original scale was calculated as .86 with Cronbach's alpha, we calculated as .84 in our study.

Academic Intrinsic Motivation Scale: To measure the intrinsic motivation level, which is a reflection of eagerness to learn, the scale that was developed by Shia (1998) and adapted into the Turkish language by Uyulgan and Akkuzu (2014) was used. The scale consists of 23 items with four sub-dimensions as the need of success ( 6 items), social acceptance ( 9 items), fear of failure (4 items), and mastery ( 4 items). The participants answered the survey items by marking one of the options from (1) does not correspond at all to (7) corresponds exactly. The minimum and maximum scores that can be obtained from the scale are 23 and 161, respectively. Higher scores indicate higher levels of intrinsic motivation. EFA and CFA results of original scale showed that the factor loads varied between .41 and .76, the four-factor model yielded good and acceptable fit index values and it was decided as a valid measurement tool. For internal consistency measures, Cronbach's alpha of the original scale was calculated as .77 ; we calculated the Cronbach's alpha as .84.

Aitken Academic Procrastination Scale: The scale was developed by Aitken (1982) to assess students' tendency to procrastinate their academic duties and responsibilities. The scale was adapted into Turkish by Balkıs (2006). This one-factor tool consists of 16 items scored on a 5- 
point Likert-type scale. The participants answered the survey items by marking one of the options from (1) definitely wrong to (5) definitely true. The minimum and maximum scores that can be obtained from the scale are 5 and 80, respectively. Lower scores indicate a lower tendency to procrastinate, and higher scores indicate a higher tendency to procrastinate. EFA and CFA results of original scale showed that the factor loads varied between .39 and .79 and the one-factor structure explained $38 \%$ of the total variance. The original scale had good fit index values and was confirmed as a valid assessment tool in CFA results. While the internal consistency of the original scale was calculated as .82 via Cronbach's alpha, in our study, we calculated the Cronbach's alpha as .87 .

\section{Data Collection and Analysis}

The data for this study were collected by the authors in the 2017-2018 academic year, between November 2017 and January 2018. Prior to giving their responses, the participants were informed that participation in this study was voluntary, their responses shall be kept confidential and will be used only for research purposes, and they could stop or discontinue their participation at any time without any penalty. Responding to the assessment tools took an average of 20 minutes.

SPSS 22.0 and LISREL 8.80 software packages were used for the analysis of the data. Prior to the analysis, the accuracy of the data, missing values and outliers were examined (Tabachnick $\&$ Fidell, 2014). To determine the accuracy of the data, minimum-maximum values were analyzed for each variable, and it was determined that all variables varied within the expected value ranges. No missing values were found in the dataset and Mahalanobis distance values were calculated to determine outliers. Accordingly, 6 surveys were excluded from the dataset since they contain outliers. In the following stages of the data analysis, assumptions of linearity and normality were examined, and it was decided that the dataset was suitable to perform mediator variable analysis. Prior to the mediator analysis, latent variable measurement models were tested. The mediator variable analysis was tested with SEM.

\section{Findings}

Descriptive statistics about the variables used in the measurement model, the measurement model, and finally, the SEM findings regarding the mediating effect of academic intrinsic motivation on the relationship between college students' academic self-efficacy and dispositional hope levels and academic procrastination are presented in this section.

Table 2. The correlations between the variables included in the measurement model, Mean and Standard Deviation Values

\begin{tabular}{|c|c|c|c|c|c|c|c|c|c|c|c|c|}
\hline Variables & $\begin{array}{l}\text { Sub } \\
\text { factors }\end{array}$ & 1 & 2 & 3 & 4 & 5 & 6 & 7 & 8 & 9 & $\bar{x}$ & $S d$ \\
\hline \multirow{4}{*}{ ASE } & 1. $\mathrm{AE}$ & & & & & & & & & & 12.62 & 3.34 \\
\hline & 2. APL & $.61 * *$ & & & & & & & & & 11.46 & 3.31 \\
\hline & 3. CAP & $.65^{* *}$ & $.81^{* *}$ & & & & & & & & 32.41 & 8.05 \\
\hline & 4. NA & $.33^{* *}$ & $.31^{* *}$ & $.33 * *$ & & & & & & & 33.70 & 6.88 \\
\hline AIM & $\begin{array}{l}\text { 5. SA } \\
\text { 6. MA }\end{array}$ & $\begin{array}{l}.20^{* *} \\
.34^{* *}\end{array}$ & $\begin{array}{l}.17^{* *} \\
.33^{* *}\end{array}$ & $\begin{array}{l}.21^{* *} \\
.32^{* * *}\end{array}$ & $\begin{array}{l}.19 * * \\
.52 * *\end{array}$ & $.36^{* *}$ & & & & & $\begin{array}{l}31.61 \\
19.51\end{array}$ & $\begin{array}{l}7.61 \\
5.42\end{array}$ \\
\hline \multirow{2}{*}{ DH } & 7. PT & $.42 * *$ & $.31^{* *}$ & $.37 * *$ & $.38^{* *}$ & $.19^{* * *}$ & $.41^{* *}$ & & & & 24.81 & 5.18 \\
\hline & 8. AT & $.42^{* *}$ & $.48 * *$ & $.49 * *$ & $.41 * *$ & $.12 *$ & $.32^{* *}$ & $.62 * *$ & & & 23.69 & 4.71 \\
\hline $\mathbf{A E}$ & $\begin{array}{l}\text { 9. AP1 } \\
10 . \mathrm{AP} 2\end{array}$ & $\begin{array}{l}-.15^{*} \\
-.12^{*}\end{array}$ & $\begin{array}{l}-.27 * * \\
-.34 * *\end{array}$ & $\begin{array}{l}-.18^{* *} \\
-.25^{* *}\end{array}$ & $\begin{array}{l}-.35 * * \\
-.32 * *\end{array}$ & $\begin{array}{l}-.14 * * \\
-.17 * *\end{array}$ & $\begin{array}{l}-.30^{* *} \\
-.31 * *\end{array}$ & $\begin{array}{l}*-.21 * * \\
*-.29 * *\end{array}$ & $\begin{array}{l}*-.34 * * \\
*-.37 * *\end{array}$ & $* .81 * *$ & $\begin{array}{l}19.91 \\
18.45\end{array}$ & $\begin{array}{l}6.18 \\
5.57\end{array}$ \\
\hline
\end{tabular}


Not: $p<.05^{*}, p<.01^{* *}$. (ASE: Academic Self Efficacy [AE: academic effort, APL: Academic planning, CAP: coping with academic problems]; AIM: Academic Intrinsic Motivation [NA: a need of success, SA: social acceptance, MA: mastery]; DH: Dispositional Hope [PT: pathways thoughts, AT: agency thoughts]; AP: Academic Procrastination [AP1: academic procrastination 1; AP2: academic procrastination 2]).

According to the descriptive statistics about the variables used in the measurement model given in Table 2, need of success, mastery, agency thoughts, and academic planning were the variables with the highest correlation (moderate and negatively correlated) to academic procrastination $\left(p<.01^{* *}\right)$. Other variables displayed low negative correlation with academic procrastination $\left(p<.05^{*}, p<.01^{* *}\right)$. Sub-dimensions of academic self-efficacy were positively and highly; sub-dimensions of academic intrinsic motivation were positively (low, moderate, and highly); sub-dimensions of dispositional hope were positively and highly; and finally, two sub-variables of academic procrastination were positively and highly correlated $(p<.01 * *)$. Furthermore, significant positive correlations (low and moderate) were found between subdimensions of both academic self-efficacy and dispositional hope to sub-dimensions of academic intrinsic motivation $\left(p<.05^{*}, p<.01^{* *}\right)$. Moreover, moderate and significant positive correlations were determined between sub-dimensions of academic self-efficacy and sub-dimensions of dispositional hope $(p<.01 * *)$.

High and significant correlations were observed between the sub-dimensions of coping with academic problems and academic planning, between sub-dimensions of the academic procrastination scale. The reason for this result may be the dividing of the academic procrastination scale, which has originally one-factor structure, into two factors to use as a variable in the SEM analysis. Moreover, it can be argued that it will not pose a problem for testing the structural equation model since significant correlations (low and moderate) exist between other scales and the observed variables. To avoid a multiple connection problem in SEM analysis, correlations should not be very high (Kline, 2015).

\section{SEM Analysis}

\section{Measurement Models for Latent Variables}

Prior to SEM analysis, the assumptions of the test of the mediating effects should be examined. As Anderson and Gerbing (1988) proposed, these assumptions are tested in two ways. Firstly, the measurement test model should have acceptable or high fit index values. After determining the measurement model yielded acceptable fit indices, the structural model can be tested. In the current study, before testing the mediating model proposed using academic selfefficacy (ASE), academic intrinsic motivation (AIM), academic procrastination (AP) and dispositional hope $(\mathrm{DH})$ variables, the measurement model of these variables were examined as given in Fig. 2: 


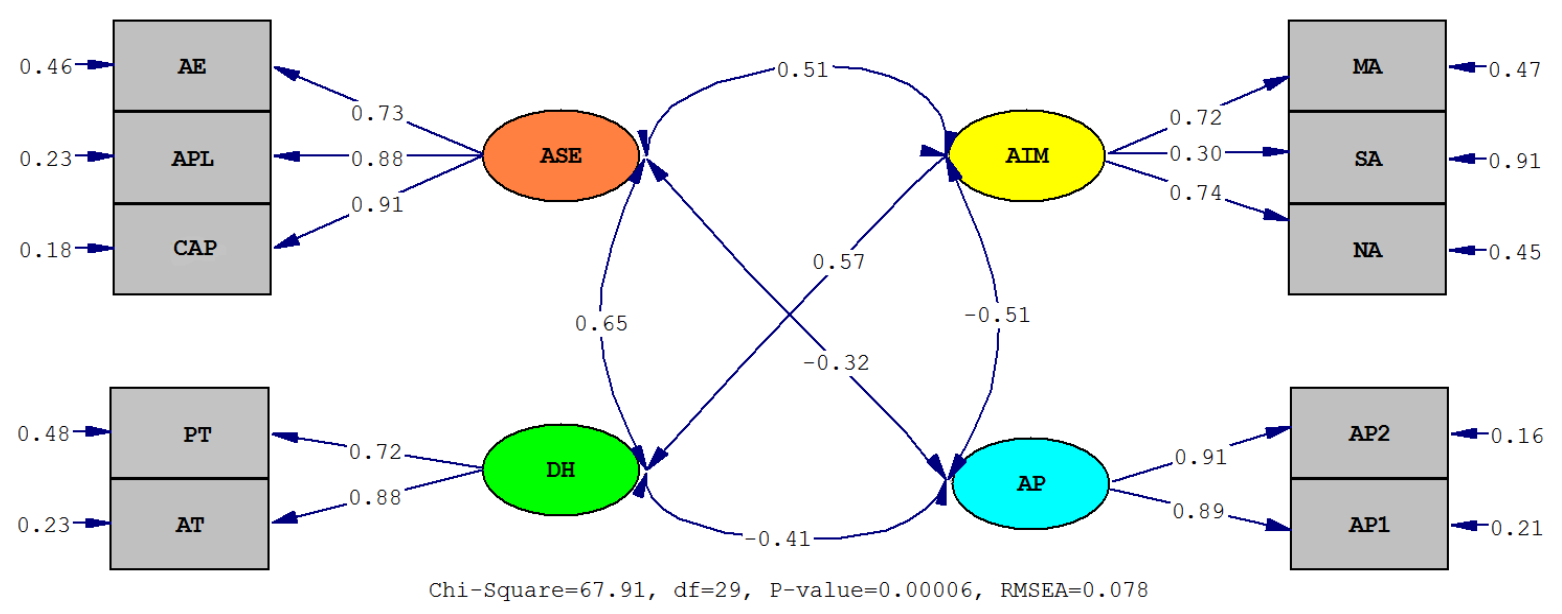

Figure 2. Standardized Path Coefficients for The Measurement Model (ASE: Academic Self Efficacy [AE: academic effort, APL: Academic planning, CAP: coping with academic problems]; AIM: Academic Intrinsic Motivation [NA: a need of success, SA: social acceptance, MA: mastery]; DH: Dispositional Hope [PT: pathways thoughts, AT: agency thoughts]; AP: Academic Procrastination [AP1: academic procrastination 1; AP2: academic procrastination 2]).

The measurement model includes four latent variables and 10 observed variables representing these four latent variables. The observed variables of academic effort, academic planning, and coping with academic problems represent the latent variable "academic self-efficacy"; need of success, social acceptance, and mastery represent the latent variable "academic intrinsic motivation"; pathways thoughts and agency thoughts represent the latent variable "dispositional hope"; academic procrastination 1 and academic procrastination 2 represent the latent variable "academic procrastination". Although the latent variable academic procrastination has a onefactor structure, it was grouped under two observed variables. Kline (2015) suggests dividing one-factor measurement tools under observed groups for models in which latent and observed variables are used together.

As seen in Fig. 2, the path coefficients between the latent variable academic procrastination and academic self-efficacy, academic intrinsic motivation, and dispositional hope were negative (moderate and high) $-.37 ;-.43$, and -.54 , respectively. The $t$ values were calculated as follows: between academic intrinsic motivation and academic self-efficacy was 17.29; between academic intrinsic motivation and dispositional hope was 11.07; between academic procrastination and academic self-efficacy was -5.97 ; between academic procrastination and dispositional hope was -8.55 ; between academic intrinsic motivation and academic procrastination was -6.58 . Accordingly, all $t$ values were found to be significant. The model fit indexes $\left(\chi^{2} / d f=2.34\right.$, RMSEA $=.078$, SRMR $\left.=.047, \mathrm{CFI}=.97, \mathrm{NFI}=.96, \mathrm{GFI}=.94\right)$ were found to be acceptable and good (Hu \& Bentler, 1999; Kline, 2015). In the following stage, the mediating effect analysis was performed with this confirmed measurement model using the SEM. The findings obtained are given in Fig. 3. 


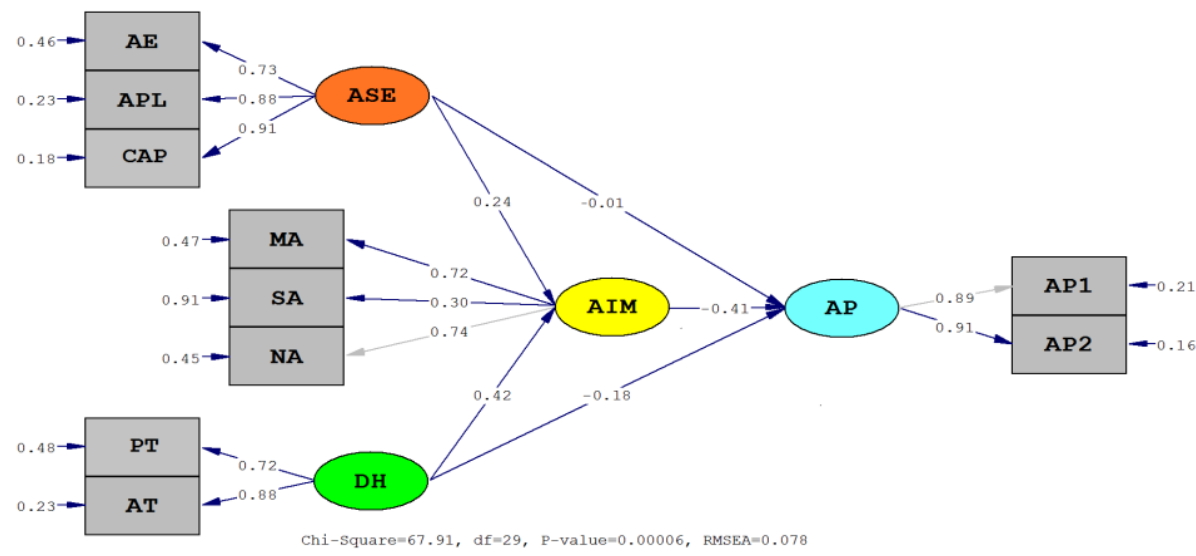

Figure 3. Standardized Path Coefficients for The Structural Model

Standardized path coefficients for the structural equation model are shown in Fig. 3. The model fit $\left(\chi^{2} / d f=\right.$, RMSEA $=.078$, SRMR $\left.=.047, \mathrm{CFI}=.97, \mathrm{NFI}=.96, \mathrm{GFI}=.94\right)$ were determined as acceptable and good. For mediating effect test, the assumptions proposed by Baron and Kenny (1986) were tested. In this regard, academic self-efficacy and dispositional hope were related to academic procrastination. According to the second assumption, academic self-efficacy and dispositional hope were related to academic intrinsic motivation. The third assumption is that academic intrinsic motivation was related to academic procrastination. Based on the findings obtained, all these assumptions were met. According to the fourth assumption, the correlation between independent variable(s) and dependent variable(s) is expected to decrease or not significant while testing the structural equation model. A partial mediating effect is accepted when the correlation decrease; if the correlation decreases up to the level where it is no longer significant, a complete mediation effect occurs.

While testing the mediation effect of academic intrinsic motivation, it was found that the correlations between both academic self-efficacy and dispositional hope with academic procrastination were not significant. Because the standardized beta coefficient for the path from academic self-efficacy to academic procrastination was decreased from .37 to .01 and $t$ value was no longer significant; and the standardized beta coefficient for the path from dispositional hope to academic procrastination was decreased from .54 to .18 and $t$ value was no longer significant. Accordingly, the complete mediation effect of academic intrinsic motivation on the relationship between academic self-efficacy and dispositional hope was determined. Regarding the total effects of the model, it was found that the standardized total effect of academic selfefficacy and dispositional hope on academic intrinsic motivation were .24 and .42 , respectively; the effect of the mediator variable on academic procrastination was -.41; academic self-efficacy was -.10; dispositional hope was -.35. Regarding the indirect effects, it was determined that the indirect effect of academic self-efficacy on academic procrastination was $-.09(t=-.07 ; p>.05)$ and the indirect effect of dispositional hope on academic procrastination was $-.17(t=-1.52 ; p$ $>.05)$. For the complete mediating effect, it can be argued that dispositional hope had a higher effect than academic self-efficacy.

\section{Discussion and Conclusions}

This paper presents the mediating effect analysis of academic intrinsic motivation on the relationship between college students' academic self-efficacy and dispositional hope levels. Considering the first three sub-problems together, it was determined that the premise variable academic self-efficacy directly predicts academic procrastination, which is the dependent 
variable of dispositional hope and the mediating variable intrinsic motivation. Furthermore, the premise variables academic self-efficacy and dispositional hope directly predict the mediating variable students' academic intrinsic motivation. Our findings are consistent with previous studies indicating students' academic self-efficacy and dispositional hope directly predict academic procrastination and negative relationships exist between them (Mohammadipour \& Rahmati, 2016; Moshtaghi \& Moayedfar, 2017, Odac1 \& Kaya, 2019; Seo, 2008; Tripathi et al., 2015). Similar to our results, Kandemir (2010) showed the direct prediction role of college students' academic self-efficacy on academic procrastination behaviors through a cause-andeffect relationship. Roesch et al. (2010) found a negative relationship between both dispositional hope and stress with procrastination and the authors revealed the positive outcomes of being hopeful. According to these findings, as students' self-efficacy and dispositional hope levels increase, their procrastination behavior decrease. These findings might suggest that hopeful students seek ways to achieve their goals, make plans, and do not exhibit procrastination behaviors since they expect that they will be successful in their tasks. Academic self-efficacy also reduced procrastination behaviors just like hope. Since academic self-efficacy is a belief that they will successfully accomplish a task or event (Bandura, 1986; 1997), students with high academic self-efficacy may not have a tendency to withdraw or fear of failure, which are the sources of procrastination behavior. Thus, they can focus on accomplishing a task successfully, instead of procrastinating that event or task.

The some studies (Alemdağ et al., 2014; Tekke \& Y1ldı, 2020) reported similar findings as in our current results indicating academic self-efficacy predicts intrinsic motivation. Furthermore, based on our results which were consistent with previous reports showing that a positive correlation exists between students' motivation and hope levels, it can be claimed that as students' hope levels increase, their motivation increase (Pala, 2019; Ulukan, 2020; Yeşiltaş, 2020). Accordingly, as students' hope levels increase, their intrinsic motivation can increase. Considering that motivation is an aspect of hope, students with higher levels of hope might study harder, try different ways to access learning sources and make more effort.

Balk1s's (2006) study showing that motivational sources are important predictors of students' procrastination behavior is an indicator of the relationship between motivation and procrastination. Similarly, in a study carried out by Akpur (2017) with college students, a negative relationship was found between academic motivation and academic procrastination. A students' high intrinsic motivation can increase the pleasure taken from their tasks and activities and accordingly, procrastination behaviors may decrease. In the opposite case, since students will be less satisfied in extrinsically motivated situations or mandatory tasks, more procrastination behaviors can be observed.

The final sub-problem of this study is both supported theoretically and with our results indicating academic self-efficacy and dispositional hope predict academic intrinsic motivation and academic procrastination. Furthermore, we found that academic intrinsic motivation predicts academic procrastination. According to the model tested in our study, college students' academic intrinsic motivation had a complete mediation effect on the relationship between both academic self-efficacy and dispositional hope with academic procrastination. Accordingly, it can be argued that academic procrastination behaviors decrease as students' academic selfefficacy, dispositional hope and academic intrinsic motivation levels increase. Consisted with the model confirmed in the current study, previous studies pointed out that hope and selfefficacy are predictors of academic procrastination (Moshtaghi \& Moayedfar, 2017; Steel, 2007; Tripathi et al., 2015). The most outstanding study among these is the study by Malkoç and Kesen Mutlu (2018). Similar to our model, they determined the mediating effect of 
academic intrinsic motivation on the relationship between academic self-efficacy and academic procrastination. Furthermore, similar results were obtained in a study by Katz et al. (2014), the authors found the mediation effect of academic intrinsic motivation on the relationship between students' academic self-efficacy and academic procrastination. Consistent with our findings, Akbay and Gizir (2010) showed that students' academic self-efficacy and academic motivation are predictor variables of academic procrastination. Since dispositional hope, which is associated with motivation, is also included in our model, we can argue that a powerful model was confirmed in our study.

In a study conducted with students and adults (Alexander \& Onwuegbuzie, 2007), the authors found that hope is a powerful predictor of academic procrastination accordingly, individuals with relatively low levels of hope also have low levels of self-efficacy and therefore, they exhibit academic procrastination behaviors. Similar to our findings, Koca and Dadand1 (2019) determined the mediation effect of academic intrinsic motivation on the relationship between academic self-efficacy and academic success; Alemdağ et al. (2014) emphasized that as academic self-efficacy increases, students' academic intrinsic motivation increases. Based on these reports, it can be said that the variables included in our model were supported by the relevant literature.

Finally, the structural equation model indicated that higher levels of self-efficacy and dispositional hope in students result in increased intrinsic motivation and reduced academic procrastination. In other words, according to the mediation model, when students' self-efficacy and dispositional hope levels decrease, their academic intrinsic motivation decreases and this leads to a tendency to academic procrastination. Academic self-efficacy and dispositional hope reduce procrastination behavior. However, when the mediation effect of academic intrinsic motivation was included in our model, the effect of self-efficacy and dispositional hope on academic procrastination decrease up to a level of not significant. Therefore, a complete mediation effect was determined. Accordingly, as students' self-efficacy and dispositional hope levels increase, they develop more intrinsic motivation. As a student develop more intrinsic motivation, they may exhibit a willingness to become a master in a task or event and to have comprehensive knowledge of that task or event. The students accomplish these activities or tasks not out of necessity but with pleasure, thus they would not exhibit procrastination behavior.

\section{Implications and recommendations for future studies}

The findings obtained in this paper provide valuable insights into the predictors of procrastination tendency in students who suffer from procrastination. These findings are important as they provide information to university administrations, university career and psychological counseling services and policymakers, and especially students about the ways to reduce the sources of academic procrastination. It was considered important for university administrations to increase the practices that support students' academic self-efficacy and hope and to develop new models and programs. In this regard, if students are able to choose courses suitable for their own abilities and interests, and easy access to information and sources related to their field, students' academic self-efficacy will increase. The number of college students in Turkey increase day by day. Therefore, students have to compete more than in previous years to find and get into a job. The practices of Career Centers and Guidance and Psychological Counseling Services in universities about post-graduation job opportunities, career options, and ways of versatile personal development can increase both academic self-efficacy and hope levels of students. Thus, students can be motivated more for their classes and activities. 
Further studies may examine the relationships between academic self-efficacy or dispositional hope with academic procrastination via multi-group SEM. The effect of gender and age on the relationship between academic intrinsic motivation and academic procrastination may be examined. In addition to its mediating role obtained in this study, the effect of academic intrinsic motivation on academic procrastination can be examined through different variables. Furthermore, although the complete mediation effect of academic intrinsic motivation on the relationship between both academic self-efficacy or dispositional hope with academic procrastination was determined in our study, other studies may examine mediating effect of other variables such as subjective well-being, emotion regulation, self-esteem, and psychological resilience. The model proposed in our study can be tested at different education levels in further studies. This study is limited to college students. Therefore, the study results should be evaluated in the context of college students. Academic performance or experiences can differ at different periods of life. Since our data were obtained within a single period, this study is limited to the responds of students representing their situation only at that period.

\section{References}

Aitken, M. E. (1982). A personality profile of the college student procrastinator. (Doctoral dissertation). University of Pittsburgh, Pittsburgh.

Akbay, S., \& Gizir, C. (2010). Academic procrastination among university students according to gender: the role of academic motivation, academic self-efficacy and academic attributional style. Mersin University Journal of the Faculty of Education, 6(1), 60-78.

Akpur, U. (2017). Predictive and explanatory relationship model between procrastination, motivation, anxiety and academic achievement. Eurasian Journal of Educational Research, 17(69), 221-21.

Alemdağ, C., Erman, Ö., \& Yılmaz, A. K. (2014). Preservice physical education teachers' academic motivation and academic self-efficacy. Hacettepe Journal of Sport Sciences, 25(1), 23-35.

Alexander, E. S., \& Onwuegbuzie, A. J. (2007). Academic procrastination and the role of hope as a coping strategy. Personality and Individual Differences, 42(7), 1301-1310.

Anderson, J. C. and Gerbing, D. W. (1988). Structural equation modeling in practice: A review and recommended two-step approach. Psychological Bulletin, 103(3), 411-423.

Balk1s, M. (2006). The relationships between student teachers' procrastination behaviors, thinking and decision making styles. (Doctoral dissertation). Dokuz Eylül University, İzmir.

Balkıs, M., \& Duru, E. (2009). Prevalence of academic procrastination behavior among preservice teachers, and its relationship with demographics and individual preferences. Journal of Theory and Practice in Education, 5(1), 18-32.

Balkıs, M., Duru, E., Buluş, M., \& Duru, S. (2006). An investigation of the academic procrastination among university students in related to various variables. Ege Journal of Education, 7(2), 57-73.

Bandura, A. (1977). Self-efficacy: Toward a unifying theory of behavioral change. Psychological Review, 84, 191-215.

Bandura, A. (1986). Social foundations of thought and action: A social cognitive theory. Englewood Cliffs, NJ: Prentice Hall.

Bandura, A. (1995). Exercise of personal and collective efficacy in changing societies. In A. Bandura (Ed.), Self-efficacy in changing societies (pp. 1-45). New York: Cambridge University Press.

Bandura, A. (1997). Self-efficacy: The exercise of control. New York: Freeman. 
Baron, R. M., \& Kenny, D. A. (1986). The moderator-mediator variable distinction in social psychological research: Conceptual, strategic, and statistical considerations. Journal of Personality and Social Psychology, 51(6), 1173-1182.

Beck, B. L., Koons, S. R., \& Milgrim, D. L. (2000). Correlates and consequences of behavioral procrastination: The effects of academic procrastination, self-consciousness, selfesteem and self-handicapping. Journal of Social Behavior and Personality, 15(5), 3-13.

Brownlow, S., \& Reasinger, R. D. (2000). Putting off until tomorrow what is better done today: Academic procrastination as a function of motivation toward college work. Journal of Social Behavior and Personality, 15(5), 15-34.

Day, V., Mensink, D., \& O'Sullivan, M. (2000). Patterns of academic procrastination. Journal of College Reading and Learning, 30(2), 120-134.

Ellis, A. \& Knaus, W. J. (2000). Overcoming procrastination. New York: New American Library.

Ferrari, J. R., \& Beck, B. L. (1998). Affective responses before and after fraudulent excuses by academic procrastinators. Education, 118, 529-537.

Fraenkel, J. R., Wallen, N. E., \& Hyun, H. H. (2012). How to design and evaluate research in education (8th ed.). New York: McGraw-Hill.

Hill, M. B., Hill, D. A., Chabot, A. E., \& Barrall, J. F. (1978). A survey of college faculty and student procrastination. College Student Journal, 12, 256-262.

Hu, L., \& Bentler, P. M. (1999). Cut off criteria for fit indexes in covariance structure analysis: Conventional criteria versus new alternatives. Structural Equation Modeling: A Multidisciplinary Journal, 6(1), 1-55.

Kandemir, M. (2010). A model explaining academic procrastination behavior. (Master thesis). Gazi University, Ankara.

Katz, I., Eilot, K., \& Nevo, N. (2014). I'll do it later: Type of motivation, self-efficacy and homework procrastination. Motivation and Emotion, 38(1), 111-119.

Kline, R. B. (2015). Principles and practice of structural equation modeling (4th ed.). New York: Guilford Press.

Koca, F., \& Dadand1, İ. (2019). The mediation roles of test anxiety and academic motivation in the relationship between academic self-efficacy and academic achievement. Elementary Education Online, 18(1), 241-252.

Liu, L., \& Cheng, L. (2018). The relationship between self-efficacy and achievement motivation in adolescents: A moderated mediating model of self-identity and hope. Psychology and Behavioral Sciences, 7(3), 69-76.

Malkoç, A., \& Kesen Mutlu, A. (2018). Academic self-efficacy and academic procrastination: Exploring the mediating role of academic motivation in Turkish university students. Universal Journal of Educational Research, 6(10): 2087-2093.

Martin, K. K. (2007). Measuring hope: Is hope related to problem solving and criminal behaviour in offenders? (Master's thesis). University of Toronto, Toronto.

Martin, T. R., Flett, G. L., Hewitt, P. L., Krames, L., \& Szanto, G. (1996). Personality correlates of depression and health symptoms: A test of a self-regulation model. Journal of Research in Personality, 30(2), 264-277.

Milgram, N. N., Mey-Tal, G., \& Levison, Y. (1998). Procrastination, generalized or specific, in college students and their parents. Personality and Individual Differences, 25(2), 297316.

Mohammadipour, M., \& Rahmati, F. (2016). The predictive role of social adjustment, academic procrastination and academic hope in the high school students' academic burnout. Interdisciplinary Journal of Education, 1(1), 35-45.

Moltafet, G. (2020). Direct and indirect effect of personality traits on hope: the mediating role of academic motivation. International Journal of Behavioral Sciences, 13(4), 167-172. 
Moshtaghi, S., \& Moayedfar, H. (2017). The role of psychological capital components (hope, optimism, resiliency and self-efficacy) and achievement goals orientation in predicting academic procrastination in students. Biquarterly Journal of Cognitive Strategies in Learning, 5(8), 61-78.

Odac1, H., \& Kaya, F. (2019). Perfectionism and the role of hopelessness on procrastination behavior: A research on university students. Journal of Higher Education and Science, 9(1), 43-51.

Orpen, C. (1998). The causes and consequences of academic procrastination: a research note. Westminster Studies in Education, 21, 73-78.

Pajares, F., \& Graham, L. (1999). Self-efficacy, motivation constructs, and mathematics performance of entering middle school students. Contemporary Educational Psychology, 24(2), 124-139.

Pala, G. (2019). Mediating role of psychological needs in the relationship of adolescent identity development, academic motivation and hope (Master thesis). Hacettepe University, Ankara.

Pintrich, P. R., \& Zusho, A. (2002). The development of academic self-regulation: the role of cognitive and motivational factors. In A. Wigfield \& J. S. Eccles (Eds.), Development of achievement motivation (pp. 249-284). San Diego, CA: Academic Press.

Pychyl, T. A. (2013). Solving the procrastination puzzle: A concise guide to strategies for change. New York: Penguin Group.

Pychyl, T. A., Morin, R. W., \& Salmon, B. R. (2000). Procrastination and the planning fallacy: An examination of the study habits of university students. Journal of Social Behavior and Personality, 15(5), 135-150.

Roesch, S. C., Duangado, K. M., Vaughn, A. A., Aldridge, A. A., \& Villodas, F. (2010). Dispositional hope and the propensity to cope: a daily diary assessment of minority adolescents. Cultural Diversity and Ethnic Minority Psychology, 16(2), 191-198.

Ryan, R. M., \& Deci, E. L. (2000). Self-determination theory and the facilitation of intrinsic motivation, social development, and well-being. American Psychologist, 55(1), 68-78.

Senécal, C., \& Guay, F. (2000). Procrastination in job-seeking: An Analysis of motivational processes and feelings of hopelessness. Journal of Social Behavior \& Personality, 15(5), 267-283.

Senecal, C., Koestner, R., \& Vallerand, R. J. (1995). Self-regulation and academic procrastination. The Journal of Social Psychology, 135(5), 607-619.

Solomon, L. J., \& Rothblum, E. D. (1984). Academic procrastination: Frequency and cognitive behavioral correlates. Journal of Counseling Psychology, 31, 503-509.

Seo, E. H. (2008). Self-efficacy as a mediator in the relationship between self-oriented perfectionism and academic procrastination. Social Behavior and Personality: an international journal, 36(6), 753-764.

Shia, R. M. (1998). Assessing academic intrinsic motivation: A look at student goals and personal strategy. Retrieved from http://www.cet.edu/research/student.html.

Sirois, F., \& Pychyl, T. (2013). Procrastination and the priority of short-term mood regulation: Consequences for future self. Social and Personality Psychology Compass, 7(2), 115127.

Sparks, G. M. (1988). Teachers' attitudes toward change and subsequent improvements in classroom teaching. Journal of Educational Psychology, 80(1), 111-117.

Snyder, C. R. (2002). Hope theory: Rainbows in the mind. Psychological Inquiry, 13(4), 249275.

Snyder, C. R., Harris, C., Anderson, J. R., Holleran, S. A., Irving, L. M., Sigmon, S. T., Yoshin obu, L., Gibb, J., Langelle, C., \& Harney, P. (1991). The will and ways: Development 
and validation of an individual-differences measure of hope. Journal of Personality and Social Psychology, 60(4), 570-585.

Snyder, C. R., LaPointe, A. B., Crowson, J. J., \& Early, S. (1998). Preferences of high and lowhope people for self-referential input. Cognition \& Emotion, 12 (6), 807-823.

Steel, P. (2007). The nature of procrastination: A meta-analytic and theoretical review of quintessential self-regulatory failure. Psychological Bulletin, 133(1), 65-94.

Tabachnick, B. G., \& Fidell, L. S. (2014). Using multivariate statistics (6th ed.). Harlow: Pearson Education.

Tarhan, S., \& Bacanl1, H. (2015). Adaptation of Dispositional Hope Scale into Turkish: Validity and reliability study. The Journal of Happiness \& Well-Being, 3(1), 1-14.

Tekke, M., \& Yildiz, A. (2020). Relationship between self-esteem, self-efficacy and intrinsic motivation with openness to experience: Meta-analysis. Electronic Journal of Social Sciences, 19(74), 828-837.

Tice, D. M., \& Baumeister, R. F. (1997). Longitudinal study of procrastination, performance, stress, and health: The costs and benefits of dawdling. Psychological Science, 8, 454458.

Tripathi, S. R., Kochar, A., \& Dara, P. (2015). Role of self-efficacy and hope in academic procrastination among undergraduate students. Indian Journal of Positive Psychology, 6(4), 376-379.

Ulukan, M. (2020). Investigation of students studying in different secondary education institutions physical activity participation and dispositional hope levels. Mediterranean Journal of Sport Science, 3(1), 202-218.

Urban, T. (2013). Why procrastinators procrastinate. Retrieved from http://waitbutwhy.com.

Uyulgan, M. A., \& Akkuzu, N. (2014). An overview of student teachers' academic intrinsic motivation. Educational Sciences: Theory \& Practice, 14(1), 7-32.

Uzun Özer, B. (2009). Academic procrastination in group of high school students: Frequency, possible reasons and role of hope. Turkish Psychological Counseling and Guidance Journal, 4(32), 12-19.

Uzun Özer, B., Demir, A., \& Ferrari, J. R. (2009). Exploring academic procrastination among Turkish students: Possible gender differences in prevalence and reasons. The Journal of Social Psychology, 149(2), 241-257.

Wang, J. H., \& Guthire, T. J. (2004). Modeling the effect of intrinsic motivation, extrinsic motivation, amount of reading, and past reading achievement on text comprehension between U.S. and Chinese students. Reading Research Quarterly, 39(2), 162-186.

Yeşiltaş, M. D. (2020). The role of academic motivation and general procrastination on students' academic procrastination. Osmaniye Korkut Ata University Journal of Economics and Administrative Sciences, 4(1), 123-133. 